the students, thus blending the paediatric and the psychiatric perspectives. We also tackle issues like attitudes of doctors, the doctor-patient relationship, the ward structure and routine, and the skills of talking with children and their parents. Role-play again is often used; for example, about how to talk to a leukaemic child and/or his parents. In the past we permitted students to select cases they wanted to present but recently we have given them eight topics to choose from:

(1) a common non-life-threatening acute illness, e.g. gastroenteritis

(2) a common acute problem with an alarming association: e.g. convulsions

(3) a common, non-life-threatening chronic physical illness, e.g. asthma

(4) a worrying problem in the newborn, e.g. congenital abnormality

(5) a terminal illness, e.g. leukaemia

(6) a chronic long-term physical disorder with a serious prognosis, e.g. beta thalassaemia

(7) a chronic long-term neuro-developmental disorder, e.g. cerebral palsy

(8) a problem of adolescence, e.g. overdose.

This integrated method of teaching is a good example of the philosophy of the medical school which I mentioned earlier. We do it in such a harmonious manner that we serve as good role models for our observing students as to how child psychiatrists and paediatricians can work together fruitfully.

Although child psychiatry is basically a postgraduate, and even to a large extent a post-membership subject, we aim to make it recognisable clinically and academically at the undergraduate level. Probably it is no exaggeration to say that the older generation of doctors in Hong Kong have very little idea about childhood psychiatric morbidity. This results in misdiagnoses and mismanagement of such children. Moreover, the sub-specialty of child psychiatry remains something of a puzzle to these doctors. Hence, we consider conveying to doctors, and even more so to future doctors, the relevance of child psychiatry. This wide visibility of child psychiatry in our undergraduate curriculum is feasible largely because of our philosophy of teaching which, as I have already mentioned, is that our aim is not to turn students into psychiatrists, and even less so, child psychiatrists, but rather to contribute to making them better doctors. But by so doing, we have gained rather than lost. We believe that not only have we achieved our goals to a large extent but we have also managed to attract more young doctors into psychiatry.

\title{
The use of videos to illustrate child psychopathology to medical students
}

\author{
M. E. Garralda, Senior Lecturer and Honorary Consultant in Child and Adolescent \\ Psychiatry, University of Manchester Department of Psychiatry, Booth Hall \\ Children's Hospital, Blackley, Manchester
}

As a relative newcomer to the medical undergraduate curriculum, child psychiatry is still looking for ways in which to best convey its message to students. There is fairly general agreement that this should combine opportunities to assess children or at least to observe the psychiatric assessment of problems and to impart basic information on child development and psychopathology.

A variety of methods are used from traditional didactic lectures to large groups of students, to experiential methods, with role play exercises reenacting childhood, family, medical and therapeutic situations. Discussion groups on communicating with children and systematic training in the use of simple behavioural techniques have also been described (Black, 1985; Cottrell, 1987).
Whatever the methods favoured, there are practical constraints. These include difficulties in obtaining sufficient time within the highly condensed and competitive undergraduate curriculum and the relatively small numbers of child psychiatric teachers. In practice there are wide variations in the amount of time allocated to child psychiatry in different medical schools (Cottrell, 1987).

This report describes an expansion of a child psychiatric teaching programme which was achieved by making use of videotapes. The teaching programme to undergraduates on which this was based and the response by medical students has been described before (Garralda, 1984). The programme takes place during the students' eight week paediatric placement and it consists of introductory lectures in child 
psychiatry, seminars where children with psychiatric problems or with psychological problems associated with physical illness are interviewed and discussed by the students, and attendances to out-patient assessments of new cases. A feedback exercise showed that the students were interested and receptive to this teaching. It identified a need for more exposure to the common child psychiatric problems, as a result of which additional out-patient attendances were organised. The feedback also highlighted the fact that videos, which had occasionally been shown as part of the case presentations, were especially popular with students. It was therefore decided to increase their use.

Videos have long been popular as teaching aids in psychiatry (Roeske, 1979) and they have also become popular in child psychiatric practice. Visual images have a special impact of their own and they can convey immediacy and the complexity of the interactions involved in child psychiatric interventions in a unique way. Whereas the use of recorded lectures is an efficient but not particularly popular method of teaching (Paegle, Wilkinson \& Connelly, 1980), videos have been successfully used to assess verbal transactions during paediatric consultations (Pantell, Stewart, Dias et al, 1982) to break down interpersonal and counselling skills (i.e. interest/ empathy/genuineness; offering advice/interpreting or encouraging; movements and posture; interpersonal distance) (Schonover, Bassuk, Smith \& Gaskill, 1983), and to teach psychiatric interview techniques to doctors (Goldberg, Steele \& Smith, 1979). However, caution in their use has been advocated as "the sole use of films to teach interview techniques may form attitudes towards patients which preclude effective rapport-building" (Hunt, Dagadakis, Ward \& Wies, 1981). In child psychiatry, Zeitlin (1982) and Thompson (1985) have described their use for teaching medical students and emphasised the need for editing and again for tapes to be an added, and not the sole, source of clinical materials.

We were inspired in this work by colleagues in our Adult Psychiatric Department who, as part of the psychiatric clerkship, had found it useful to allow students to supplement the teaching with selfteaching video-tapes demonstrating clinical syndromes. These had proved clearly popular (Goldberg, Benjamin \& Creed, 1983). We started to record interviews with children and parents on video systematically and encouraged students to watch them in their own time. Because they were not doing so, it was suggested that we allocate some time for them to watch the taped interviews with a registrar working in our unit. This was not to be regarded as a seminar or formal teaching occasion, only those students interested should come and, in order not to encroach into their paediatric curriculum, we selected a lunchtime period. To our surprise, all the medical students came for the first session and continued to do so subsequently. They appeared to profit from it and the registrars seemed to enjoy it too. Soon the meetings became part of our teaching routine.

Because of their often unusual and striking nature, it became clear that this teaching occasion lent itself to demonstrating certain severe conditions best (i.e. psychotic and neurotic states). These conditions were well known to the registrars in their adult versions as they all had experience in adult psychiatry and they soon started to prepare introductory acetates and handouts outlining the main clinical features.

\section{The video sessions}

A pattern has developed of eight weekly sessions lasting about 50 minutes and facilitated by a psychiatric registrar. When they first join our unit, registrars are introduced to the method and are given a list of topics and videotapes with which they are to become familiar and which will form the basis of their teaching. They attend one session where the teaching model is demonstrated. Short extracts of interviews with children are interspersed with discussion with the students of their observations on the child's behaviour and communications and on the techniques the interviewer uses to facilitate them. The videos are of good enough technical quality to maintain a favourable attentive attitude from students.

The video sessions have three general aims:

(a) to demonstrate the main clinical features of a number of childhood psychiatric conditions;

(b) to give "life to the child behind the condition" especially by showing the children themselves describing their symptoms;

(c) to make the students aware of ways of exploring the sorts of difficulties that children describe and the way they express these concerns at interview.

\section{Issues demonstrated in the sessions}

Our videos on autistic children demonstrate interviews with children and their parents and give students an opportunity to appreciate the peculiar way in which autism affects close social interactions. One of the videos shows an alert and inquisitive 5 year-old at a pre-verbal stage of development who is erratic and distant in his emotional responsiveness; the parents' apparent hopelessness and distant attitude to the boy are demonstrated and this usually engages the students in a discussion about the environmental aetiological factors in autism. Another tape shows a verbal 10 year old who describes in a stilted, monotonous voice his idiosyncratic interests and demonstrates his limitations in emphathic social communication. A third tape demonstrates an interview with an intelligent, adolescent autistic boy, his 
obsessive preoccupations, difficulties in relationships and suffering.

We demonstrate schizophrenic-type psychosis in a very ill young adolescent who shows perplexity, suspiciousness and aggression, bizarre behaviour and use of language and in a young girl with inappropriate giggling and romantic delusions. The strange and qualitatively unusual nature of these conditions is clearly shown, as well as the adolescent-type preoccupations and attitudes which have become distorted in the psychotic process.

Our tapes on neurotic disorders demonstrate obsessive neurosis; hysterical neuroses; anorexia nervosa; and school phobia. Seeing an 8 year-old girl with obsessional preoccupations and actions highlights the differences between the usual childhood obsessional traits and the disorder whereby an otherwise perfectly normal looking, thinking and behaving child reveals anxious ruminations about contamination and death which she recognises as irrational and opposes, albeit not successfully, and from which she gains relief by repeating certain actions.

The videos on school refusal and anorexia nervosa are self-explanatory. The children interviewed describe their anxiety symptoms or preoccupation connected with going to school or with food and there is little difficulty in pointing out the basic features of the conditions. The sessions, however, allow some exploration of the different ways in which a problem can present in individual children. A videotape of an 11 year old severely depressed and retarded girl with anorexia nervosa, for example, demonstrates the connection between anorexia and depression and techniques for eliciting preoccupations from a noncommunicative withdrawn child.

The curious nature of hysteria is shown in interviews with children with hysterical disorders of limb or sensory function. Our limping 13 year-old girl shows a lack of concern about her symptoms, an oldfashioned conformist attitude to life and relationships, a serious preoccupation with school work, and a hostile resistance to psychological interchange which are often features of hysterical symptoms in children; whereas the boy, who seems clearly to be pretending his sensory deficits, is seen at a six-month follow-up to have deteriorated down the pathway of a neurodegenerative disorder.

We have also found video teaching useful to demonstrate additional issues of relevance in child psychiatry. Firstly, to show that antisocial symptoms can be associated with unhappiness and be a response to stress: at a first interview, an 11 year-old boy who has been truanting, stealing and has been aggressive and argumentative towards his mother, with skilled guidance by the doctor comes gradually to manifest a deep sadness about the loss of his father through the break-up of his parents' marriage. There is also an opportunity to see an 8 year-old girl whose stealing had similarly been related to family losses, but who on recovery relates her feelings about first coming for a psychiatric assessment, "I thought they was going to put me away", and recounts aspects of her individual play therapy sessions. Secondly, we demonstrate family therapy in a tape containing comments about the therapeutic process by the therapist which is therefore largely self-explanatory.

The format allows flexibility for registrars to use different videos and they tend to use those on patients they have interviewed personally or tapes demonstrating visually striking conditions such as the Gilles de la Tourette syndrome.

\section{Why have these sessions proved so popular with students and registrars?}

We carry out a regular feedback exercise from students on the teaching, and video sessions have proved consistently popular and memorable to them. The registrars themselves have consistently been dedicated and enthusiastic. Why and what are the advantages of this type of teaching?

(a) Our videos show children with severe conditions at a time when students are dealing with severe paediatric problems, their teaching is disease- and severity-oriented and they are therefore particularly likely to respond to the matching dramatic and serious nature of these psychological presentations. Since psychological problems of children tend to mirror their adult counterparts, the more severe their presentation, the more are registrars comfortable teaching about them as opposed to teaching about the more common and intrinsically more interactive and complex psychiatric problems of children.

(b) The rarity of these problems makes it unlikely for students to have an opportunity to see cases during their eight week paediatric training or even for registrars to see enough to become familiar with them through fresh case experience alone. Storing videos is therefore especially advantageous.

(c) In my previous report (Garralda, 1984) I noted that discussion of psychiatric problems without exposure to the children themselves appeared to "obscure the children behind the symptoms". This problem is reduced because of the vividness of the video presentation and the spontaneity of children communications.

(d) The thirst for knowledge characteristic of this stage of medical student training makes students susceptible to the didactic teaching which accompanies the sessions. The registrars themselves preparing for membership exams share this interest in factual knowledge. 


\section{Possible snags}

(a) We regard this teaching as useful when associated with other teaching occasions in which students have an opportunity to observe in vivo assessments of children with more mundane conditions, and to discuss with senior child psychiatrists aspects of the multi-factorial nature of disturbed psychiatric disorders. On its own, this method could give a false impression of the nature of child psychiatry.

(b) Because the teaching is imparted by junior staff rotating through our department at relatively short intervals (every six months) whose major training is in adult psychiatry, a good deal of ready-made well-prepared video and case-vignette material is needed, together with close supervision and guidance by the senior teachers, particularly at the initial stages of teaching.

All in all and since the use of video as a teaching aid is already widespread in medical schools (Cottrell, 1987), the model described here could be relatively easily implemented as a complementary aid in the task of teaching child psychiatry to medical students. It may also assist in generating future adult psychiatrists' knowledge and enthusiasm about this area of psychiatry as "even while they teach, men learn" (Seneca).

\section{Acknowledgements}

I am grateful to Dr Mary Eminson and Professor David C. Taylor for their comments.

\section{References}

Black, D. (1985) What medical students need to know about child psychiatry. Newsletter of University Teachers of Psychiatry, Summer 1985, 12-16.

COTTRELL, D. (1987) A survey of undergraduate teaching of child and adolescent psychiatry in the United Kingdom. Bulletin of the Royal College of Psychiatrists, 11, 265-268.

GARRALDA, E. (1984) Teaching child psychiatry to medical students: students' feedback. Bulletin of the Royal College of Psychiatrists, 8, 171-172.

Goldberg, D. P., Steele, J. J. \& SmITH, C. (1979) Teaching psychiatric interview techniques to family doctors. Acta Psychiatrica Scandinavica, Suppl. 285, 62, 41-47.

- Benjamin, S. \& Creed, F. (1983) Symposium on the teaching of psychiatry. England: University of Manchester. British Journal of Psychiatry, 142, 350-357.

Hunt, D. D., Dagadakis, C. J., Ward, N. G. \& Rirs, R. (1981) Live 'versus' videotaped interview. Journal of Medical Education, 56, 916-918.

PaEgle, R. D., Wilkinson, E. J. \& Connelly, M. B. (1980) Videotaped versus traditional lectures for medical students. Medical Education, 14, 387-393.

Pantell, R. H., Stewart, T. J., Dias, J. K., Wells, P. \& Ross, W. (1982) Physician communication with children and parents. Paediatrics, 70, 396-402.

ROESKE, N. C. A. (1979) The medium and the message: Development of videotapes for teaching psychiatry. The American Journal of Psychiatry. 136, 1391-1397.

Schonover, S. C., Bassuk, E. L., Smith, R. \& Gaskill, J. (1983) The use of videotape programs to teach interpersonal skills. Journal of Medical Education, 58, 805-810.

ThOMPsON, M. (1985) Child psychiatry for undergraduates: A trainee's experience in a teaching programme. Bulletin of the Royal College of Psychiatrists, 9, 95-96.

ZeITLIN, H. (1982) Teaching child psychiatry to undergraduates in London University. Unpublished manuscript. 